\title{
Transcription factor binding at enhancers: shaping a genomic regulatory landscape in flux
}

\section{Robert-Jan Palstra* and Frank Grosveld}

Department of Cell Biology, Erasmus MC University Medical Center, Rotterdam, Netherlands

\section{Edited by:}

Michèle Amouyal, Centre National de la Recherche Scientifique, France

\section{Reviewed by:}

Michèle Amouyal, Centre National de la Recherche Scientifique, France Jim Davie, University of Manitoba, Canada

\section{*Correspondence:}

Robert-Jan Palstra, Department of Cell Biology, Erasmus MC University Medical Center, Dr. Molewaterplein 50, 3015 GE Rotterdam, Netherlands. e-mail: r.palstra@erasmusmc.nl
The mammalian genome is packed tightly in the nucleus of the cell. This packing is primarily facilitated by histone proteins and results in an ordered organization of the genome in chromosome territories that can be roughly divided in heterochromatic and euchromatic domains. On top of this organization several distinct gene regulatory elements on the same chromosome or other chromosomes are thought to dynamically communicate via chromatin looping. Advances in genome-wide technologies have revealed the existence of a plethora of these regulatory elements in various eukaryotic genomes. These regulatory elements are defined by particular in vitro assays as promoters, enhancers, insulators, and boundary elements. However, recent studies indicate that the in vivo distinction between these elements is often less strict. Regulatory elements are bound by a mixture of common and lineage-specific transcription factors which mediate the long-range interactions between these elements. Inappropriate modulation of the binding of these transcription factors can alter the interactions between regulatory elements, which in turn leads to aberrant gene expression with disease as an ultimate consequence. Here we discuss the bi-modal behavior of regulatory elements that act in cis (with a focus on enhancers), how their activity is modulated by transcription factor binding and the effect this has on gene regulation.

\section{Keywords: enhancer, transcription factor, chromatin looping, transcription, cis-regulation}

\section{INTRODUCTION}

Expression of genes is to a large extent directed by regulatory sequences within the promoters of genes. However, early transfection experiments led to the realization that promoters alone were not enough to direct the proper expression of genes. The first enhancers described were SV40 viral repeat sequences that are able to boost expression of a rabbit $\beta$-globin construct (Banerji et al., 1981). This enhancement of expression occurred independent of the orientation and location of the enhancer sequence within the reporter construct and this observation became the operational definition of enhancer elements. Soon after the description of viral enhancer sequences the first mammalian enhancer sequences were discovered within the human immunoglobulin heavy Chain locus (Banerji et al., 1983) and it turned out that this enhancer sequence acts in a tissue-specific fashion. Since the first enhancer discovery in humans, many more enhancers have been discovered in different organisms and it is estimated that over 1 million enhancers reside in the human genome (Heintzman et al., 2009). It is also becoming clear that enhancers are marked by the binding of specific chromatin modification factors and the presence of specific histone modifications (Maston et al., 2012). Recent work also suggests that not only protein-coding genes are under the influence of enhancers but that microRNA genes might also be under long-range developmental control (Sheng and Previti, 2011). Although we have come a long way in the 30 years since the first discovery of enhancers, their discovery still remains a challenging task and the mechanism of enhancer action is still largely unknown.

\section{ENHANCER DISCOVERY BY MAPPING TRANSCRIPTION FACTOR BINDING SITES AND CHROMATIN MODIFICATIONS}

Discovery of enhancers has always been a formidable task. DNAseI hypersensitivity mapping was the method of choice since it was observed that regulatory regions within the genome are hypersensitive to DNAseI digestion (Wu, 1980). However, this method was tedious, requiring careful titration of DNAseI concentration, restriction digestion, Southern blotting, and detection with labeled nucleotide probes which yielded only information on particular sequences or loci. The first attempts to identify enhancers on a genome-wide scale did not depend on DNaseI but involved enhancers traps (Hamada, 1986). In this method, a selectable reporter gene driven by an enhancer dependent promoter is randomly integrated in to the genome. Clones in which the reporter gene has integrated within the vicinity of an enhancer can be selected and the enhancer sequences isolated. Subsequent validation of enhancer activity can be done in vitro by transiently transfecting luciferase reporter constructs in cell lines or in vivo using reporter constructs in transgenic animals. However, this method remains a laborious procedure.

With the emergence of complete sequence information from many different model organisms attempts were made to identify regulatory sequences based on sequence conservation. These bioinformatics attempts were moderately successful (MeirelesFilho and Stark, 2009). However, it has become clear that not all conserved non-coding sequences have a detectable (enhancer) activity and not all enhancers are conserved at the sequence level (Blow etal., 2010; Royo etal., 2011). Recent advances 
in genome-wide technologies like array technology and more recently high-throughput sequencing are proving to be a game changer for the genome-wide discovery of enhancers. More traditional techniques are currently combined with high-throughput sequencing technologies to identify enhancers on a genome-wide scale and novel approaches of enhancer discovery are introduced. One of the first techniques to be combined with array technology and later high-throughput sequencing as a read out was chromatin immunoprecipitation (ChIP; Barski et al., 2007; Johnson etal., 2007; Mikkelsen etal., 2007; Robertson et al., 2007) and even "old school" DNAseI hypersensitive site mapping has been combined with high-throughput sequencing in order to obtain genome-wide maps of "open" chromatin associated with regulatory regions (Sabo et al., 2006; Hesselberth et al., 2009; Bernstein et al., 2010).

Early genome-wide ChIP experiments found that enhancers are enriched in specific chromatin marks, especially high levels of $\mathrm{H} 3 \mathrm{~K} 4 \mathrm{me} 1 \mathrm{in}$ combination with low levels of H3K4me3 appeared to mark enhancer sequences (Heintzman et al., 2007). Later it was found that acetylation of histone $\mathrm{H} 3$ at lysine 27 (H3K27Ac) specifically marks active enhancers (Creyghton et al., 2010) and recently it has been reported that in T-lymphocytes di- and trimethylation of histone $\mathrm{H} 3$ at lysine 4 are also correlated with active enhancers (Pekowska et al., 2011). As many more chromatin modifications have recently been identified (Tan et al., 2011), it is to be expected that several of these novel chromatin marks associate with enhancers (Kellner et al., 2012). Transcriptional co-activators like the acetyltransferase and transcriptional co-activator p300 (Visel etal., 2009a; May etal., 2011), the ATAC histone acetyl transferase complex (Krebs et al., 2011) and the ATP-dependent chromatin remodeler CHD7 (Schnetz et al., 2009, 2010) also appear to locate at enhancers. Clusters of tissue-specific transcription factors are hallmarks of enhancers and this fact has been exploited to identify enhancers. He et al. (2011) used a set of five cardiac-specific transcription factors to identify cardiac-specific enhancers that were distinct from p300 bound enhancers. Analysis of the binding of a set of three myogenic-specific transcription factors in combination with p300 binding and enhancer-associated chromatin marks before and after muscle differentiation allowed for the identification of muscle-specific enhancers (McCord et al., 2011). Furthermore, the mysterious highly occupied target (HOT) regions which are bound by many transcription factors but lack their consensus binding motif, function as spatial and temporal enhancers in transgenic assays (Kvon et al., 2012). Conversely, mapping of tissue-restricted enhancers via chromatin marks has lead to the discovery of specific transcription factor binding signatures that correspond to monocyte differentiation states (Pham et al., 2012).

Several laboratories have defined distinct chromatin signatures associated with specific regulatory elements based on the combinatorial analysis of multiple chromatin marks and transcription factor binding patterns (Wang et al., 2008; Ram et al., 2011; Bonn et al., 2012; Cotney et al., 2012; Hoffman et al., 2012), which allows to distinguish between specific enhancer states (Rada-Iglesias et al., 2011; Zentner et al., 2011; Bogdanovic et al., 2012; Cotney et al., 2012). Novel approaches to detect regulatory genomic regions are also emerging like formaldehyde-assisted isolation of regulatory elements (FAIRE) which identifies the more "open" chromatin state associated with enhancers based on differences in phenol extractability of these regions (Giresi et al., 2007). Analysis of different genome-wide data sets is also revealing novel properties of enhancers. Global nuclear run-on followed by high-throughput sequencing (GRO-seq) data revealed that enhancers display bidirectional expression of short transcripts (Melgar et al., 2011; Wang et al., 2011), while an in depth analysis of glucocorticoid receptor (GR)-regulated enhancers revealed that they are enriched in $\mathrm{CpG}$ dinucleotides and that their methylation status is cell type-specific and correlate with the accessibility of the enhancers (Wiench et al., 2011).

High-throughput genome-wide approaches have made enhancer discovery a more amendable task. To date, most of these studies have been performed on cell lines but the first attempts to follow enhancer dynamics during development have been successful (Bogdanovic et al., 2012; Cotney et al., 2012). Given the spatial and temporal specificity of enhancers the major challenge for the future will lie in obtaining the proper tissues at the right developmental stage or state of differentiation and performing reliable ChIP-seq on the often limiting amounts of these cells (Bonn et al., 2012).

\section{TRANSCRIPTION FACTOR-MEDIATED LONG-RANGE ENHANCER-PROMOTER COMMUNICATION}

One key feature of eukaryotic enhancers is that they can be located far away from the gene they regulate. How enhancers are able to communicate with their cognate promoters remained a mystery for about two decades. A number of models were proposed which included polymerase tracking, the spreading of chromatin structures, and direct contact between separated elements. The non-contact model (polymerase tracking and chromatin spreading) postulated a role for the intervening chromatin fiber which would propagate a "signal" from the enhancer to the promoter. The contact model, better known as the looping model, proposed that the active enhancer and promoter would reside in close proximity within the nucleus while the intervening chromatin loops out. Although early in vitro experiments in prokaryotic systems provided support for the contact model [reviewed in Amouyal (1991)], the first direct in vivo evidence in eukaryotes was provided by the phenomenon of transvection in Drosophila (Tartof and Henikoff, 1991). The contact model was subsequently experimentally tested by varying the position or distance of genes in a series of experiments using the human $\beta$-globin locus (Hanscombe et al., 1991; Dillon et al., 1997).

The subsequent development of new techniques like RNA TRAP (Carter et al., 2002) and chromosome conformation capture (3C; Dekker et al., 2002) and its application to mammalian loci (Tolhuis et al., 2002) allowed the mapping of chromatin folding of gene loci. These studies on the $\beta$-globin locus clearly demonstrated that the major regulatory element of the $\beta$-globin genes, the locus control region (LCR), resides in close proximity to the genes when active while the intervening chromatin and inactive genes loop out (Carter et al., 2002; Tolhuis et al., 2002). These interactions are developmental stage-specific (Palstra et al., 2003) and dependent on lineage-specific transcription factors (Drissen et al., 2004; Vakoc et al., 2005). Chromatin conformations similar to the ones 
initially observed within the $\beta$-globin locus have been found in several other gene loci in different cell types generally confirming the looping model (de Wit and de Laat, 2012).

$3 \mathrm{C}$ and its derivatives are currently the method of choice to demonstrate interactions between enhancers and their target genes (de Wit and de Laat, 2012). A major limitation of $3 \mathrm{C}$ is the fact that some knowledge of the location of the regulatory elements is needed to design primers. Combining $3 \mathrm{C}$ with high-throughput sequencing allows for the unbiased discovery of novel long-range interactions of a specific locus (Soler et al., 2010), especially when combined with ChIP-derived chromatin modifications or transcription factor binding profiles as was demonstrated in a study that identified adipocyte-specific enhancers (Mikkelsen et al., 2010) and a study which identified erythroid-specific enhancers for the MYB gene (Stadhouders et al., 2011). One of the remaining drawbacks of this approach is that it still relies on a single locus for a viewpoint and is therefore not truly unbiased. A Chia-PET approach that focuses on either enhancer marks (Chepelev et al., 2012) or promoter-associated RNA polymerase II (RNA pol II; Li et al., 2012) in part circumvents this limitation. A truly unbiased method like Hi-C could in principle detect all long-range enhancer-promoter interactions in a cell population although limitations in sequencing depth and limitations of the bioinformatic tools available currently restricts the resolution of this approach (Lieberman-Aiden et al., 2009). However, taking the fast developments in high-throughput sequencing and bioinformatics analysis into account it may be in the not too distant future that enhancer-promoter interactions are routinely identified using Hi-C. In fact, a first glimpse of tissue-specific promoter-enhancer interactions has been observed in a recent Hi-C study (Dixon et al., 2012).

Binding of lineage-specific transcription factors to enhancers and promoters plays a vital role in the establishment/maintenance of long-range promoter-enhancer interactions. There appears to be a distinct set of transcription factors that tend to bind to promoters and a distinct set that tend to bind at distal regulatory elements (Lan et al., 2012). Analysis of Hi-C and ENCODE data obtained in erythroid leukemia cells indicated that in general factors bound at promoters interact with factors bound at distal sites (Lan et al., 2012). For some transcription factors their role in chromatin looping has been studied in more detail. In a knock-out mouse model of the erythroid-specific transcription factor EKLF, no long-range interactions between the $\beta$-globin LCR and $\beta$-major gene are observed and the $\beta$-globin locus adopts a chromatin conformation reminiscent of the one observed in erythroid progenitor cells (Drissen et al., 2004). Re-introduction of EKLF restores LCR- $\beta$-globin interaction and this also occurs in the absence of protein synthesis demonstrating a direct involvement of EKLF in chromatin looping (Drissen et al., 2004). A similar study on the transcription factors GATA-1 and FOG1 has shown that these factors also play a vital role in LCR- $\beta$-globin gene interaction (Vakoc et al., 2005). The role of another erythroid transcription factor, the heterodimeric NF-E2 has been more controversial. One study demonstrated that chromatin looping was independent of NF-E2 in a knock-out mouse model of the NF-E2 p45 subunit (Kooren et al., 2007) while an other study demonstrated NF-E2dependent chromatin looping in a cellular model system upon knock down of the MafK/NF-E2 p18 subunit (Du et al., 2008). Other lineage-specific factors that have been shown to play a role in chromatin looping are GATA3 and STAT6 in the T-cell lineage (Spilianakis and Flavell, 2004) and OCA-B in the B-cell lineage (Ren et al., 2011).

It is doubtful that lineage-specific DNA binding transcription factors are solely responsible for establishing enhancer-promoter interactions. Enhancer bound transcription factors recruit coactivators and general factors of which some have been shown to play a vital role in enhancer-promoter communication. One of the best studied factors is the widely expressed transcriptional cofactor Ldb1. The non-DNA-binding Ldb1 protein is able to interact with multiple transcription factors and mediates interactions between them (Matthews and Visvader, 2003). In erythroid cells, Ldb1 is part of a large complex that contains the core factors TAL1, LMO2, E2A, and GATA1 which is recruited to E boxes and GATA elements in, for example, the $\beta$-globin LCR and promoter (Wadman et al., 1997; Soler et al., 2010). Knock-down of Ldb1 in erythroid cells results in an impaired long-range interaction between the $\beta$-globin LCR and $\beta$-major promoter and a failure to activate $\beta$-major expression (Song et al., 2007). A recent report demonstrated that artificial tethering of the self association domain of Ldb1 to the $\beta$-globin promoter is able to induce a chromatin loop between the $\beta$-globin LCR and promoter and this was sufficient to induce expression of the $\beta$-globin gene (Deng et al., 2012b). Other general factors implicated in chromatin loop formation between enhancers and promoters are Brg1, the ATPase component of the SWI/SNF nucleosome remodeling complex (Kim et al., 2009) and the general transcription factor TFII-I (Ren et al., 2011). A different type but very interesting general nuclear factor involved in chromatin looping is cohesin. It is best known for its role in holding together sister chromatids during mitosis, but more recently it has been recognized that cohesin is intimately linked to transcription (Dorsett, 2011; Haering and Jessberger, 2012). The nuclear protein CCCTC-binding factor (CTCF) is thought to partition the genome in separate domains via chromatin loops preventing crosstalk between active and inactive regions (Weth and Renkawitz, 2011; Herold et al., 2012). Recently it was found that these CTCF-mediated chromatin loops are dependent on cohesin (Parelho et al., 2008; Rubio et al., 2008; Wendt et al., 2008; Wendt and Peters, 2009). Interestingly, in murine ES cells cohesin interacts with Mediator and the cohesin loading factor Nipbl and together they participate in chromatin loop formation between enhancers and promoters of ES cell-specific loci (Kagey et al., 2010). Similarly, upon differentiation of mouse erythroid leukemia (MEL) cells cohesin and Nipbl are recruited to the $\beta$-globin LCR and $\beta$-major promoter coinciding with an increase in transcription. Knock-down of one of these factors resulted in reduced chromatin looping between the $\beta$-globin LCR and promoter (Chien et al., 2012). Furthermore, the TBP core promoter associated factor TAF3 cooperates with CTCF and cohesin to mediate long-range chromatin loops between enhancers and promoters in the endoderm lineage (Liu et al., 2011).

The general picture that is emerging from these studies is that lineage-specific DNA binding transcription factors bound at promoters and enhancers recruit "looping" factors which setup 
contacts between distal enhancers and promoters. Such factors appear to form loops within more "structural" loops mediated by general factors like CTCF (Figure 1).

The fact that active enhancers reside within close proximity of the active promoters they regulate is currently well recognized. How these interactions are established remains largely unknown. Whether the formation of a chromatin loop is an actively directed process or determined by random collisions has not been elucidated. Several studies suggest that polymerization of nuclear actin might be a driving force in bringing enhancers and promoters together. For example, actin polymerization is necessary for retonic acid induced recruitment of transcription factors to an enhancer element, for the induction of HoxB transcription (Ferrai et al., 2009), for the reactivation of OCT4 during reprogramming by oocytes (Miyamoto et al., 2012), and for the re-localization of gene loci in the interphase nucleus (Chuang et al., 2006; Dundr et al., 2007). Additionally, motor-proteins like nuclear Myosin I and dynein light chain-I have also been reported to be essential for nuclear receptor-induced co-localization of gene loci ( $\mathrm{Hu}$ et al., 2008). The direct involvement of these factors in establishing enhancer-promoter chromatin loops has however not been shown. Some interpretations of the popular transcription factory hypothesis suggest an alternative actively directed process for bringing enhancers and promoters together (Papantonis and Cook, 2010; Deng et al., 2012a). In this view polymerases bound to enhancers would real-in the chromatin fiber until a promoter is encountered which is subsequently activated (West and Fraser, 2005). However, promoter-enhancer chromatin loops remain when RNA pol II transcription is pharmacologically inhibited, suggesting that such a scenario is unlikely (Mitchell and Fraser, 2008; Palstra et al., 2008).

\section{ENHANCER MODE OF ACTION}

How enhancers actually promote transcription of a gene when in close proximity remains poorly understood. What is clear is that enhancer bound transcription factors recruit co-activators either as part of an enhanceosome or flexible billboards (Alvarez et al., 2003; Arnosti and Kulkarni, 2005). In an enhanceosome a multiprotein complex is assembled at the enhancer and spacing of transcription factor binding sites is crucial for its function (Thanos and Maniatis, 1995). A similar model has been suggested for the multi-enhancer $\beta$-globin LCR where the hypersensitive

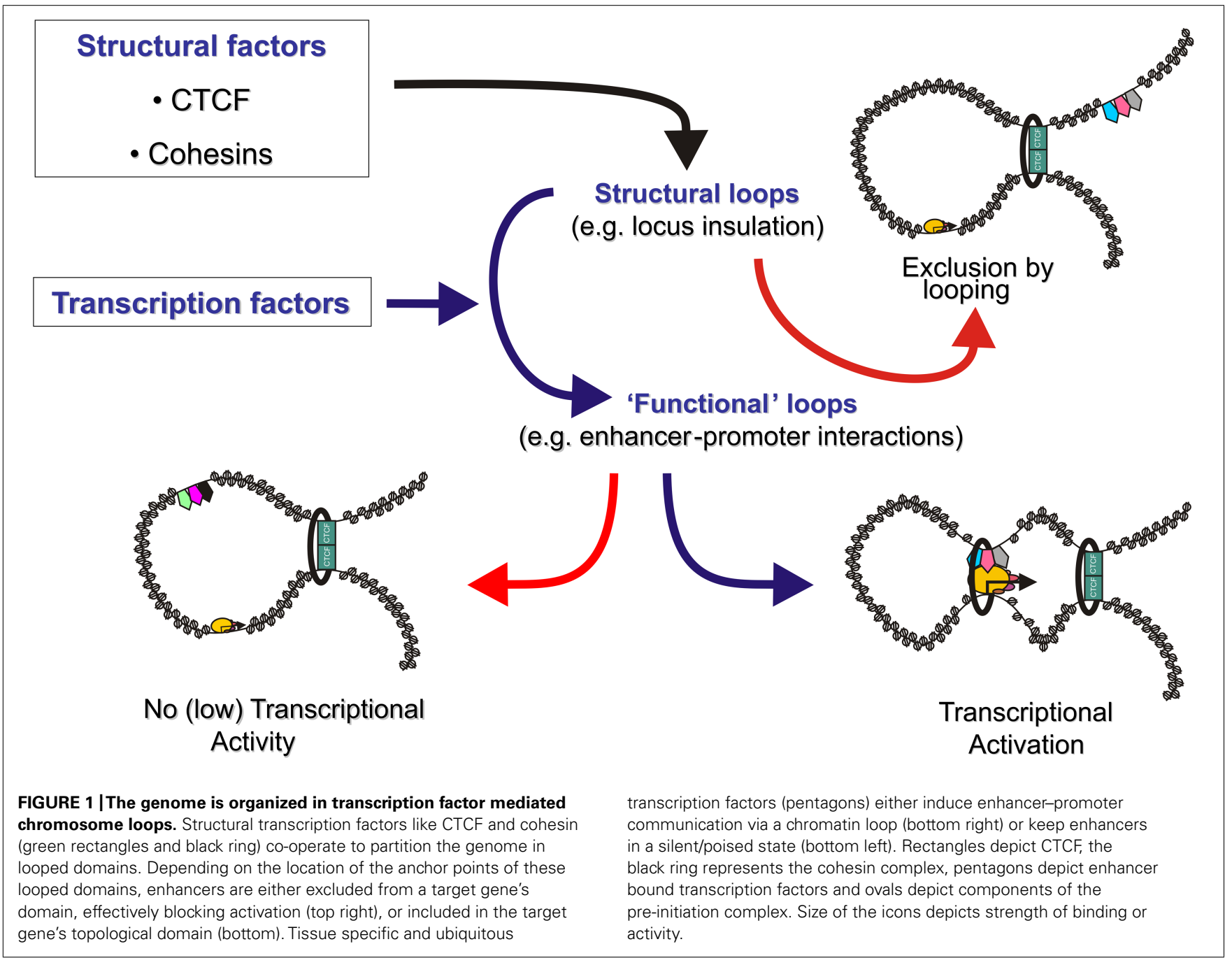


sites of the LCR are thought to form a holo complex (Ellis et al., 1996; Milot etal., 1996). Billboard enhancers are more flexible in their architecture since they consist of separate elements that individually are able to modulate transcription and the additive repressive or activating effects of these elements would determine the transcriptional outcome (Arnosti and Kulkarni, 2005).

Traditionally enhancers are thought to enhance recruitment of RNA pol II and the pre-initiation complex to promoters. It has been suggested that enhancers (or LCRs) function by simply increasing the local concentration of transcription factors, which in turn increases the efficiency of transcription (Palstra et al., 2003). Recent studies have shown that many genes contain stalled polymerases and that the transition from initiation to elongation appears to be a rate limiting step under stringent control (Nechaev and Adelman, 2011). It has therefore been suggested that enhancers play a role in facilitating this transition. Indeed, deletion of the $\beta$-globin LCR results in severely reduced phosphorylation of the RNA pol II C-terminal domain (CTD) and transcriptional elongation while pre-initiation complex (PIC) assembly and RNA pol II recruitment to the $\beta$-globin promoter was only reduced twofold (Sawado et al., 2003). The erythroid Myb gene enhancers are looped to a conserved CTCF binding site in the first intron of the Myb gene. The p-TEFb component Cdk9 is specifically recruited to the enhancer as part of the Ldb1 complex, and the conserved CTCF site in the intron marks a transition between pausing and elongating polymerases suggesting that enhancers are also essential in regulating transcriptional elongation (Stadhouders et al., 2011). Other results were obtained in a recent study were chromatin looping between the $\beta$-globin LCR and $\beta$-major gene was induced by tethering of a looping factor (Deng et al., 2012b). Recruitment of RNA pol II to the $\beta$-major promoter was restored upon induced chromatin looping while transcriptional elongation remained reduced. The lack of transcriptional elongation is in part explained by the failure to recruit and activate the $\mathrm{P}-\mathrm{TEFb}$ elongation factor in this system which lacks the crucial erythroidspecific transcription factor GATA1 (Deng et al., 2012b). Together, these studies suggest that enhancers have a function in both PIC and RNA pol II recruitment or stabilization and facilitation of the transition between initiation and elongation.

Alternative mechanisms for enhancer function have also been proposed. Recent genome-wide studies have made clear that RNA pol II is recruited to enhancers (De Santa et al., 2010; Kim et al., 2010; Koch et al., 2011) and that these enhancers are transcribed (Melgar et al., 2011; Wang et al., 2011). A role for these transcripts in enhancer function has been suggested (Orom and Shiekhattar, 2011), however their exact role remains uncertain. Although some non-coding (nc) RNAs seem to behave like classical enhancers in reporter assays (Orom et al., 2010), other observations seem to refute a direct role for the generated ncRNA transcript. The activity of the human growth hormone enhancer is for example dependent on the level of enhancer transcription but not on the structure of its ncRNA (Yoo et al., 2012). Another example where non-coding transcripts are linked to enhancer function is the Kcnq1 imprinted domain (Korostowski et al., 2011). In this case, chromatin loop formation between regulatory elements prevents Kcnq1 promoter silencing by the non-coding Kcnq1ot1 transcript. An attractive but as yet untested possibility is that the ncRNAs are involved in promoting/stabilizing the interaction between the enhancer and its target promoter by RNA binding transcription factors at the enhancer and basic complex transcription factors at the promoter. The observation that RNA pol II complexes are recruited to enhancers has lead to a model in which enhancers are able to transfer RNA pol II to promoters either via direct transfer (Leach et al., 2001) or a tracking mechanism (Zhu et al., 2007). Transfer of polymerases from enhancer sequences to promoter sequences was indeed demonstrated in an in vitro assay (Vieira et al., 2004). Convincing in vivo data to support this model are however lacking and RNA pol II is still recruited to the $\beta$-major gene in the absence of an LCR (Sawado et al., 2003).

Enhancers also seem to play a role in polycomb eviction from developmental promoters containing $\mathrm{CpG}$ islands by recruiting the histone H3K27me3 demethylase JMJD3 to the promoter (Taberlay et al., 2011; Vernimmen et al., 2011). In fact, the activity of developmental enhancers itself appears to be kept under tight control by members of the polycomb complex and several other histone methyl transferases (Svotelis et al., 2011; Whyte et al., 2012; Zhu et al., 2012). In breast cancer cells, the poised enhancer of Bcl2 is marked by $\mathrm{H} 3 \mathrm{~K} 27 \mathrm{me} 3$. Activation of this enhancer requires the inactivation of the H3K27 methylase EZH2 a member of the polycomb complex and the simultaneous recruitment of the histone H3K27me3 demethylase JMJD3 which is under hormonal control (Svotelis et al., 2011). Several enhancers that have ubiquitous activities when tested in transgenic assays are repressed in non-permissive cells by the presence of flanking regions enriched in H3K9me3 at their endogenous location (Zhu et al., 2012). Cell type-specific recruitment of the H3K9 demethylase Jmjd2d alleviates this repression. Conversely, enhancers responsible for maintaining ES cell identity have to be silenced upon differentiation, which occurs through the recruitment of the H3K4/K9 histone demethylase LSD1 (Whyte et al., 2012).

On the other hand, enhancers that have to become active in a specific lineage are kept in a poised state upon stem cell differentiation via the sequential recruitment of lineage-restricted transcription factors. The transcription factor SOX2 is for example bound at neuron-specific regulatory elements in embryonic stem cells, and is replaced by SOX3 in neuronal progenitor cells and later by SOX11 in terminal differentiated neurons (Bergsland et al., 2011).

It is very well possible that enhancer action goes beyond just one activity and that enhancers perform different tasks sequentially during cellular differentiation. Initially, enhancers will keep gene loci in a transcriptionally competent state by sequential recruitment of progressively more lineage-restricted transcription factors. At a later stage, they will assemble and stabilize a preinitiation complex at the gene promoter via chromatin looping and finally release paused polymerases through recruitment of elongation factors.

\section{SPLIT PERSONALITIES OF REGULATORY ELEMENTS}

As mentioned before, eukaryotic enhancers were operationally defined in transient transfection assays by the ability to activate a reporter gene irrespective of location and orientation relative to the promoter. This does not necessarily mean that these regulatory elements behave in a similar fashion at their native location 
in the chromatin context of a cell which is subject to a variety of external signaling cues. The activity of enhancer like elements is regulated in a strict temporal and positional manner within a developing organism. A better approach to test the enhancer like abilities of a DNA sequence is to test it linked to a reporter gene via a transgenic approach. Besides the fact that enhancers can switch between multiple active, poised, and repressed states (Creyghton et al., 2010; Rada-Iglesias et al., 2011; Zentner et al., 2011), new studies indicate that a cis-regulatory element can have multiple properties simultaneously.

Depending on the assays used, multiple distinct classes of cis-regulatory elements can be recognized (Raab and Kamakaka, 2010). Promoters are bound by transcription factors, provide an assembly point for the RNA pol II holo complex and generally designate a more or less defined directional starting point of transcription. Enhancers recruit transcription factors, they can be transcribed and are able to boost expression from a distally located promoter often in a developmental stage and tissuerestricted manner. The action of enhancers can be counteracted by enhancer blockers when placed between the enhancer and promoter. On the other hand, silencers can suppress transcription from multiple positions relative to enhancers and promoters. Finally, insulators are genetic elements that counteract the spread of heterochromatin.

As discussed above genome-wide studies have demonstrated that many enhancers recruit RNA pol II and are transcribed (De Santa etal., 2010; Kim et al., 2010). Similar observations have been made almost two decades ago for hypersensitive site 2 of the $\beta$-globin LCR (Tuan et al., 1992). Most of these enhancer transcripts can be polyadenylated but remain short and are not elongated (Kim et al., 2010). Enhancers that are located intragenic however produce long spliced and polyadenylated transcripts and may therefore function as alternative promoters (Kowalczyk et al., 2012). Promoters of tRNA genes on the other hand have been shown to act as either insulators or enhancer blocking elements in yeast (Simms et al., 2008) and mammalian systems (Raab et al., 2011), which is mediated by binding of the general RNA Pol III transcription factor TFIIIC. In Drosophila, RNA pol II promoters containing stalled RNA pol II also act as enhancer blocking elements (Chopra et al., 2009). One model for enhancer blocking function, the decoy model, postulates that enhancer blockers interfere with enhancer-promoter interaction by producing inactive interactions between the enhancer blocking element and the promoter or the enhancer. Drosophila enhancer blocking elements indeed appear to form chromatin loops with promoters (Erokhin et al., 2011). Some enhancer blockers can also act as silencers in transient transfection assays suggesting that the distinction between these two elements depends on the assay involved (Petrykowska et al., 2008). Interestingly, it has been reported that the $\beta$-globin LCR, which is normally a very strong enhancer in erythroid cells, is able to act as a repressor when placed in the right genomic context (Feng et al., 2005). Specific repressors appear to act on enhancers by interfering with loop formation between enhancers and gene promoters (Chopra et al., 2012). Replacement of an activating loop by a repressive loop has also been observed. When the c-Kit gene is active in immature erythroid cells a GATA2-dependent chromatin loop is present between an upstream enhancer and the promoter (Jing et al., 2008). Upon erythroid maturation, GATA1 replaces GATA2 and the activating enhancer-promoter chromatin loop is replaced by a repressive chromatin loop between the promoter and a downstream silencerlike element. Interestingly, several genetic studies in drosophila have shown that enhancer blockers, when placed in the right context, can enhance enhancer-promoter communication or even act as enhancer elements (Rodin et al., 2007; Maksimenko et al., 2008; Soshnev et al., 2008; Fujioka et al., 2009). These observations indicate that enhancer blockers/silencers function, like enhancers, by means of long-range chromatin interactions. In mammalians, the major protein associated with enhancer blocking function is the 11 zinc-finger transcription factor CTCF (Bell et al., 1999), which is known to mediate long-range chromatin interactions (Splinter et al., 2006). Although CTCF is most famous for its role in enhancer blocking, the protein is also involved in gene activation (Weth and Renkawitz, 2011; Herold et al., 2012). Recent genome-wide analysis of enhancer-promoter interactions have indeed indicated that CTCF is associated with a proportion of enhancers and that CTCF mediates the interaction of these enhancers with their target promoters (Handoko etal., 2011; Li et al., 2012; Taslim et al., 2012).

In summary, it seems that the attempt to impose a strict definition on regulatory elements is much more complicated than expected: enhancers can behave like promoters, promoters can act as enhancer blockers, while enhancer blockers can function as enhancers, all dependent on the genomic context of the regulatory element and the specific set of transcription factors recruited.

\section{ENHANCER TRANSCRIPTION FACTOR BINDING IN DEVELOPMENT, DISEASE, AND PHENOTYPE DIVERSITY}

Tight control of transcription is crucial for the proper development of a multi-cellular organism. Enhancers play a crucial role in ensuring the proper spatio-temporal expression of genes by integrating the action of tissue-specific transcription factors and signaling cues (Buecker and Wysocka, 2012; Ong and Corces, 2012). Given the key role that enhancers play in the proper development of multi-cellular organisms it is of no surprise that disruption of enhancer function is a major contributor to pathological states. In fact, disease driven research has been crucial in the discovery and definition of mammalian enhancers. Investigation of $\gamma \beta$-thalassemia for example led to the discovery and characterization of the "super enhancer"-like $\beta$-globin LCR (Grosveld et al., 1987). In Dutch $\gamma \beta$-thalassemia, a large deletion removes $100 \mathrm{~kb}$ upstream of the $\beta$-globin gene but leaves the $\beta$-globin gene itself intact (Kioussis et al., 1983; Wright et al., 1984; Taramelli et al., 1986). The mutant locus is in a closed chromatin state and suffers from position effects. Further analysis of the region deleted in $\gamma \beta$-thalassemia revealed strong erythroid hypersensitive sites upstream of the $\varepsilon$-globin gene (Tuan et al., 1985). Cloning of these hypersensitive sites revealed that they impose positionindependent, copy number-dependent high level expression on a $\beta$-globin transgene defining the operational properties of a LCR (Grosveld et al., 1987). Many other instances of disease causing enhancer disruptions are currently known (Kleinjan and Lettice, 2008). Translocations can either remove enhancer sequences from a locus (Kioussis et al., 1983) or place ectopic enhancers in the 
vicinity of onco-genes as is observed in non-Hodgkin's lymphoma (Hayday et al., 1984). Smaller mutations in regulatory elements are also known to contribute to hereditary disease states. For example, several point mutations as well as insertions within the sonic hedgehog ZRS long-range enhancers cause several forms of preaxial polydactyly (Albuisson et al., 2011; Laurell et al., 2012). The effects of sequence variation in enhancer regions are not always catastrophic and can be quite subtle.

In the past decade, genome-wide association studies (GWAS) have identified many single nucleotide polymorphisms (SNPs) which are statistically associated with phenotypic traits and disease states. The majority of the DNA variants identified in GWAS studies are located in non-coding regions without any known function while only a minority $(\sim 30 \%)$ potentially disrupt the function of genes (Visel et al., 2009b; 1000 Genomes Project Consortium, 2010). Often linkage with unknown causal (non-synonymous coding) DNA variants within a haplotype block is assumed to explain association of non-coding DNA variants with a given trait. However meta-analysis demonstrated that $40 \%$ of the disease associated SNPs including their haplotype blocks exclusively involve non-coding sequence (Visel et al., 2009b) suggesting that these regions have a regulatory function. Moreover, a significant proportion of GWAS SNPs overlap with B, T, and ES cell enhancers (Teng et al., 2011), multiple sclerosis associated regions are located in chromatin regions that are active in B-cells (Disanto et al., 2012) and $80 \%$ of the colorectal cancer risk SNPs overlap with colon crypt enhancer marks (Akhtar-Zaidi et al., 2012).
One can easily imagine that the presence of a SNP might lead to differences in transcription factor binding at regulatory regions which could result in phenotypic changes and even disease (e.g., cancer) due to differences in transcriptional output of the associated genes (Figure 2). A study on 10 human lymphoblastic cell lines from different individuals indeed demonstrated that $7.5 \%$ of the binding sites for NF- $\kappa \mathrm{B}$ and $25 \%$ of the RNA pol II binding sites differed between individuals (Kasowski et al., 2010). Differential binding occurred frequently at SNPs and structural variants and was often associated with changes in gene expression. Measurement of the genome-wide allelic imbalance of 24 transcription factors and the transcriptional co-factor p300 indicated that $5 \%$ of the binding sites for these factors vary depending on the sequence difference between alleles (Reddy et al., 2012). Chromatin accessibility to DNaseI also depends on genomic variation in lymphoblastoid cell lines and these differences in DNaseI hypersensitivity correlate with differences in transcription factor binding and changes in gene expression (Degner et al., 2012). These observations strongly suggest that many non-coding DNA variants are functional and mark for example enhancers for distally located genes which are involved in the trait under study. Identifying exactly which non-coding SNPs have a regulatory function has been cumbersome, mainly due to the presence of multiple linked non-coding SNPs within a haplotype block, the fact that enhancers are highly tissue- and developmental stage-specific and the lack of proper high-throughput assays to identify enhancer regions. Subsequent identification of the genes regulated by the causative SNPs

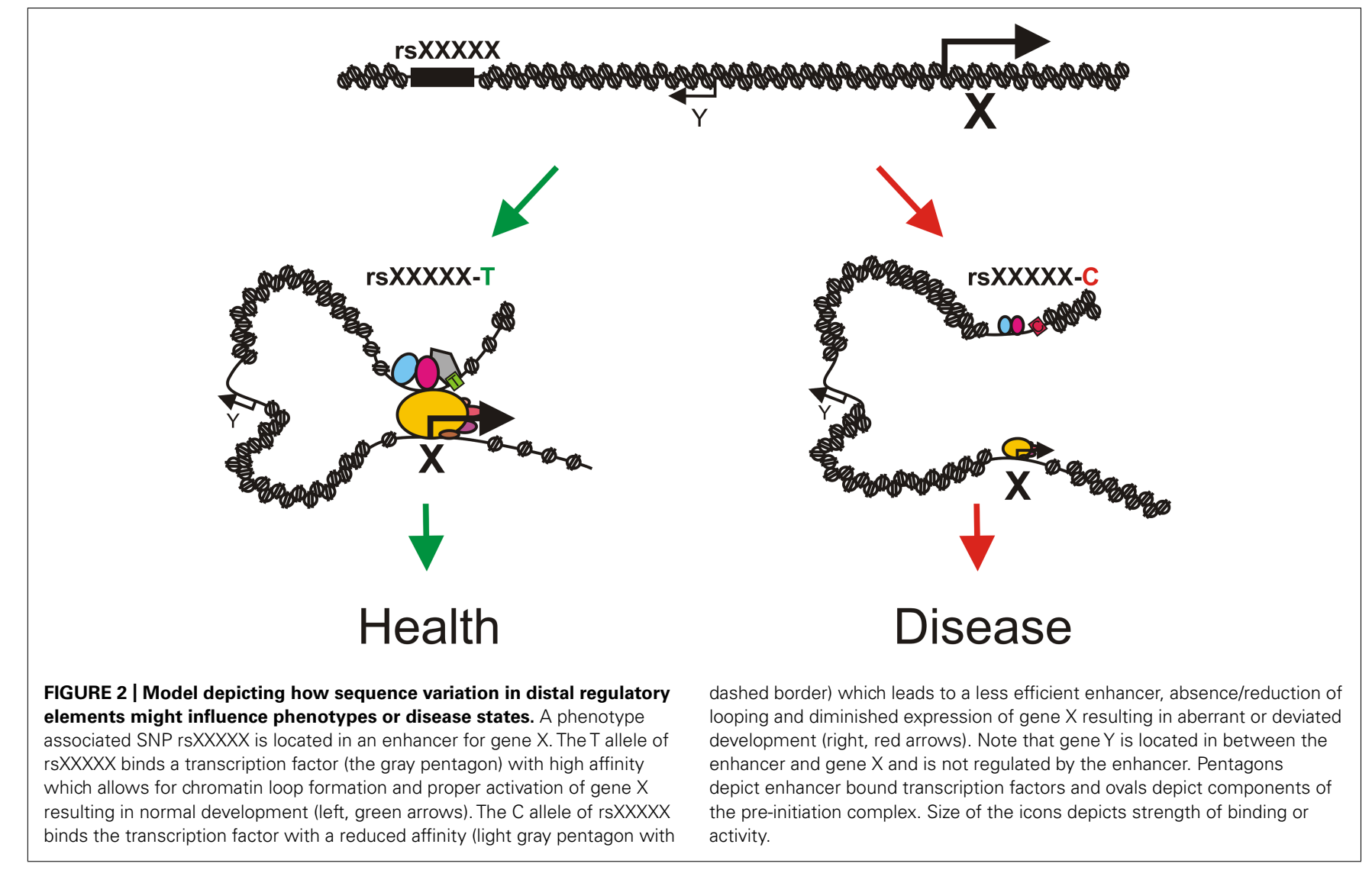


has proven to be even more difficult, since enhancers and their target genes are often separated by a significant extent of chromatin which can even contain non-target genes. The successful identification of regulatory SNPs and their linked target genes has therefore been limited to few isolated examples.

Several studies on specific risk loci support the notion that in several pathological states SNPs disrupt transcription factor binding sites within enhancers. For example, a risk allele for cleft lip disrupts an AP- $2 \alpha$ binding site in an IRF6 enhancer (Rahimov et al., 2008) and a variant linked to plasma low-density lipoprotein cholesterol and myocardial infarction creates a $\mathrm{C} / \mathrm{EBP} \alpha$ binding site which results in altered expression of the SORT1 gene in hepatocytes (Musunuru et al., 2010). Studies on other disease associated loci have demonstrated chromatin loops between the regulatory variant and the genes they regulate. The variant rs6983267 is associated with an increased risk to develop various types of cancers and several studies have demonstrated that this SNP leads to altered TCF7L2 transcription factor binding, altered enhancer activity and that this region loops to the MYC proto-oncogene (Pomerantz et al., 2009; Ahmadiyeh et al., 2010; Wright etal., 2010). Similar observations have been made for e.g., variants associated with coronary artery disease (Harismendy etal., 2011), prostate cancer (Zhang et al., 2012), and COPD (Zhou etal., 2012). Not al disruptions of enhancers by SNPs lead to increased disease susceptibility, as they can also have nonpathological effects leading to phenotypic differences. Recently we could demonstrate that rs12913832, a SNP strongly associated with pigmentation in melanocytes, results in differential transcription factor binding at a melanocyte-specific enhancer. This difference in transcription factor binding leads to allele dependent attenuated looping between the enhancer and its target the OCA2 pigment gene (Visser et al., 2012). Interestingly, allelic differences in enhancer activity are not always reflected in differential enhancer-promoter interactions (Wright et al., 2010), suggesting separate mechanisms for chromatin-loop formation and enhancer activity.

Combining genome-wide ChIP, FAIRE, and 3C highthroughput approaches with data derived from GWAS studies promises to boost the discovery of regulatory SNPs. These kinds of studies are crucial to obtain greater understanding of the impact of sequence variations on human health and disease (Chorley et al., 2008; Hawkins et al., 2010; Ernst et al., 2011) or (part of) the normal variation between individuals. Using these genome-wide approaches it will be possible to shift from just describing statistical associations between variants and traits to studies that actually discover the biology behind disease and phenotype associated non-coding variants.

\section{CONCLUSIONS AND FUTURE PROSPECTS}

Knowledge regarding enhancers and enhancer function has exploded in the past decades. Much of the early insight into

\section{REFERENCES}

Ahmadiyeh, N., Pomerantz, M. M., Grisanzio, C., Herman, P., Jia, L., Almendro, V., et al. (2010). 8q24 prostate, breast, and colon cancer risk loci show tissue-specific long-range interaction with MYC. Proc. Natl. Acad. Sci. U.S.A. 107, 9742-9746.

Akhtar-Zaidi, B., Cowper-Sal-Lari, R., Corradin, O., Saiakhova, A., Bartels, C. F., Balasubramanian, D.,

enhancer function has been obtained from painstakingly dissecting single model loci. Due to the limited amount of loci investigated, the generality of the occurrence of enhancers and their mode of action remained unclear. With the recent advent of high throughput genome-wide techniques we are now able to address the generality of these early observations. Important insights regarding enhancer-promoter communication, the occurrence of enhancers and enhancer function have been obtained. Surprisingly, the regulatory landscape is far more complex and dynamic as anticipated and it appears that each cell type has thousands of enhancers of which many are cell type-specific. Chromatin looping between regulatory elements is widely observed and appears to be a general principle for long-range enhancer-promoter communication.

However, many challenges remain. Little is known about enhancer dynamics during cellular differentiation, how signaling cascades impact on enhancer function, the role of enhancers in evolution and disease susceptibility and how enhancers actually boost transcription. Further refinement of genome-wide techniques to study enhancer function will help to answer some of these questions. Tracking transcription factor binding and chromatin looping during differentiation will provide unprecedented insights into the dynamics of enhancer action. Although genome-wide approaches are currently in vogue to investigate enhancer function, answers to some of the remaining questions will still require the careful molecular dissection of selected model loci.

Even though progress in technologies has been impressive, several limitations remain. ChIP assays require knowledge regarding the factors involved in the regulation of gene loci and good quality antibodies against these factors are not always available. The genome-wide 3C spin offs currently lack resolution, which hampers the accurate determination of the exact contact points mediating enhancer-gene interactions. Furthermore, these methods all depend on protein-protein and protein-DNA cross-linking using formaldehyde requiring a certain amount of time, setting a limit on the temporal resolution of these methods. Information regarding cell-to-cell variability is still lacking, because the majority of the current methods to study enhancer function involve batch assays on many cells. Therefore, the field would greatly benefit from the development of single cell assays to study enhancer function. The integration of genome-wide data with focused, single locus data and single cell data will undoubtedly provide us with new exciting insights into the mechanisms that shape the genomic regulatory landscape in flux.

\section{ACKNOWLEDGMENTS}

We thank Ralph Stadhouders for carefully reading the manuscript. The literature regarding transcription factors and enhancers is overwhelming and the authors wish to apologize to those whose work we were not able to cite.

et al. (2012). Epigenomic enhancer profiling defines a signature of colon cancer. Science 336, 736-739.

Albuisson, J., Isidor, B., Giraud, M., Pichon, O., Marsaud, T., David, A., et al. (2011). Identification of two novel mutations in Shh long-range regulator associated with familial preaxial polydactyly. Clin. Genet. 79, 371-377.

Alvarez, M., Rhodes, S. J., and Bidwell, J. P. (2003). Context-dependent 
transcription: all politics is local. Gene 313, 43-57.

Amouyal, M. (1991). The remote control of transcription, DNA looping and DNA compaction. Biochimie 73, 1261-1268.

Arnosti, D. N., and Kulkarni, M. M. (2005). Transcriptional enhancers: intelligent enhanceosomes or flexible billboards? J. Cell. Biochem. 94, 890-898.

Banerji, J., Olson, L., and Schaffner, W. (1983). A lymphocyte-specific cellular enhancer is located downstream of the joining region in immunoglobulin heavy chain genes. Cell 33, 729-740.

Banerii, J., Rusconi, S., and Schaffner, W. (1981). Expression of a beta-globin gene is enhanced by remote SV40 DNA sequences. Cell 27, 299-308.

Barski, A., Cuddapah, S., Cui, K., Roh, T. Y., Schones, D. E., Wang, Z., et al. (2007). High-resolution profiling of histone methylations in the human genome. Cell 129, 823-837.

Bell, A. C., West, A. G., and Felsenfeld, G. (1999). The protein CTCF is required for the enhancer blocking activity of vertebrate insulators. Cell 98, 387-396.

Bergsland, M., Ramskold, D., Zaouter, C., Klum, S., Sandberg, R., and Muhr, J. (2011). Sequentially acting Sox transcription factors in neural lineage development. Genes Dev. 25, 2453-2464.

Bernstein, B. E., Stamatoyannopoulos, J. A., Costello, J. F., Ren, B., Milosavljevic, A., Meissner, A., et al. (2010). The NIH Roadmap Epigenomics Mapping Consortium. Nat. Biotechnol. $28,1045-1048$.

Blow, M. J., Mcculley, D. J., Li, Z., Zhang, T., Akiyama, J. A., Holt, A., et al. (2010). ChIP-Seq identification of weakly conserved heart enhancers. Nat. Genet. 42, 806-810.

Bogdanovic, O., Fernandez-Minan, A., Tena, J. J., De Lacalle-Mustienes, E., Hidalgo, C., Van Kruysbergen, I., etal. (2012). Dynamics of enhancer chromatin signatures mark the transition from pluripotency to cell specification during embryogenesis. Genome Res. doi: 10.1101/gr.134833.111 [Epub ahead of print].

Bonn, S., Zinzen, R. P., Girardot, C., Gustafson, E. H., Perez-Gonzalez, A., Delhomme, N., et al. (2012). Tissue-specific analysis of chromatin state identifies temporal signatures of enhancer activity during embryonic development. Nat. Genet. 44, $148-156$.

Buecker, C., and Wysocka, J. (2012). Enhancers as information integration hubs in development: lessons from genomics. Trends Genet. 28, 276-284. Carter, D., Chakalova, L., Osborne, C. S., Dai, Y. F., and Fraser, P. (2002). Long-range chromatin regulatory interactions in vivo. Nat. Genet. $32,623-626$.

Chepelev, I., Wei, G., Wangsa, D., Tang, Q., and Zhao, K. (2012). Characterization of genome-wide enhancer-promoter interactions reveals co-expression of interacting genes and modes of higher order chromatin organization. Cell Res. 22, 490-503.

Chien, R., Zeng, W., Kawauchi, S., Bender, M. A., Santos, R., Gregson, H. C., et al. (2012). Cohesin mediates chromatin interactions that regulate mammalian \{beta\}-globin expression. J. Biol. Chem. 286, 1787017878.

Chopra, V. S., Cande, J., Hong, J. W., and Levine, M. (2009). Stalled Hox promoters as chromosomal boundaries. Genes Dev. 23, 1505-1509.

Chopra, V. S., Kong, N., and Levine, M. (2012). Transcriptional repression via antilooping in the Drosophila embryo. Proc. Natl. Acad. Sci. U.S.A. 109, 9460-9464.

Chorley, B. N., Wang, X., Campbell, M. R., Pittman, G. S., Noureddine, M. A., and Bell, D. A. (2008). Discovery and verification of functional single nucleotide polymorphisms in regulatory genomic regions: current and developing technologies. Mutat. Res. 659, 147-157.

Chuang, C. H., Carpenter, A. E., Fuchsova, B., Johnson, T., De Lanerolle, P., and Belmont, A. S. (2006). Long-range directional movement of an interphase chromosome site. Curr. Biol. 16, 825-831.

Consortium, G. P. (2010). A map of human genome variation from population-scale sequencing. Nature 467, 1061-1073.

Cotney, J., Leng, J., Oh, S., Demare, L. E., Reilly, S. K., Gerstein, M. B., et al. (2012). Chromatin state signatures associated with tissue-specific gene expression and enhancer activity in the embryonic limb. Genome Res. 22, 1069-1080.

Creyghton, M. P., Cheng, A. W., Welstead, G. G., Kooistra, T., Carey, B. W., Steine, E. J., et al. (2010). Histone H3K27ac separates active from poised enhancers and predicts developmental state. Proc. Natl. Acad. Sci. U.S.A. 107, 21931-21936.

De Santa, F., Barozzi, I., Mietton, F., Ghisletti, S., Polletti, S., Tusi, B. K., etal. (2010). A large fraction of extragenic RNA pol II transcription sites overlap enhancers. PLoS
Biol. 8, e1000384. doi: 10.1371/journal.pbio.1000384

de Wit, E., and de Laat, W. (2012). A decade of $3 \mathrm{C}$ technologies: insights into nuclear organization. Genes Dev. 26, 11-24.

Degner, J. F., Pai, A. A., Pique-Regi, R., Veyrieras, J. B., Gaffney, D. J., Pickrell, J. K., et al. (2012). DNase I sensitivity QTLs are a major determinant of human expression variation. Nature 482, 390-394.

Dekker, J., Rippe, K., Dekker, M., and Kleckner, N. (2002). Capturing chromosome conformation. Science 295, 1306-1311.

Deng, B., Melnik, S., and Cook, P. R. (2012a). Transcription factories, chromatin loops, and the dysregulation of gene expression in malignancy. Semin. Cancer Biol. doi: 10.1016/j.semcancer.2012.01.003 [Epub ahead of print].

Deng, W., Lee, J., Wang, H., Miller, J., Reik, A., Gregory, P. D., et al. (2012b). Controlling longrange genomic interactions at a native locus by targeted tethering of a looping factor. Cell 149, 1233-1244.

Dillon, N., Trimborn, T., Strouboulis, J., Fraser, P., and Grosveld, F. (1997). The effect of distance on long-range chromatin interactions. Mol. Cell 1, 131-139.

Disanto, G., Sandve, G. K., BerlangaTaylor, A. J., Morahan, J. M., Dobson, R., Giovannoni, G., et al. (2012). Genomic regions associated with multiple sclerosis are active in B cells. PLoS ONE 7, e32281. doi: 10.1371/journal.pone.0032281

Dixon, J. R., Selvaraj, S., Yue, F., Kim, A., Li, Y., Shen, Y., et al. (2012). Topological domains in mammalian genomes identified by analysis of chromatin interactions. Nature 485 , 376-380.

Dorsett, D. (2011). Cohesin: genomic insights into controlling gene transcription and development. Curr. Opin. Genet. Dev. 21, 199-206.

Drissen, R., Palstra, R. J., Gillemans, N., Splinter, E., Grosveld, F., Philipsen, S., et al. (2004). The active spatial organization of the beta-globin locus requires the transcription factor EKLF. Genes Dev. 18 , 2485-2490.

Du, M. J., Lv, X., Hao, D. L., Zhao, G. W., Wu, X. S., Wu, F., etal. (2008). MafK/NF-E2 p18 is required for beta-globin genes activation by mediating the proximity of LCR and active beta-globin genes in MEL cell line. Int. J. Biochem. Cell Biol. 40, 1481-1493.

Dundr, M., Ospina, J. K., Sung, M. H., John, S., Upender, M., Ried, T., et al.
(2007). Actin-dependent intranuclear repositioning of an active gene locus in vivo. J. Cell Biol. 179, 1095-1103.

Ellis, J., Tan-Un, K. C., Harper, A., Michalovich, D., Yannoutsos, N., Philipsen, S., et al. (1996). A dominant chromatin-opening activity in $5^{\prime}$ hypersensitive site 3 of the human beta-globin locus control region. EMBO J. 15, 562-568.

Ernst, J., Kheradpour, P., Mikkelsen, T. S., Shoresh, N., Ward, L. D., Epstein, C. B., etal. (2011). Mapping and analysis of chromatin state dynamics in nine human cell types. Nature 473 , 43-49.

Erokhin, M., Davydova, A., Kyrchanova, O., Parshikov, A., Georgiev, P., and Chetverina, D. (2011). Insulators form gene loops by interacting with promoters in Drosophila. Development 138, 4097-4106.

Feng, Y. Q., Warin, R., Li, T., Olivier, E., Besse, A., Lobell, A., et al. (2005). The human beta-globin locus control region can silence as well as activate gene expression. Mol. Cell. Biol. 25, 3864-3874.

Ferrai, C., Naum-Ongania, G., Longobardi, E., Palazzolo, M., Disanza, A., Diaz, V. M., et al. (2009). Induction of HoxB transcription by retinoic acid requires actin polymerization. Mol. Biol. Cell 20, 3543-3551.

Fujioka, M., Wu, X., and Jaynes, J. B. (2009). A chromatin insulator mediates transgene homing and very long-range enhancer-promoter communication. Development 136, 3077-3087.

1000 Genomes Project Consortium. (2010). A map of human genome variation from population-scale sequencing. Nature 467, 1061-1073.

Giresi, P. G., Kim, J., Mcdaniell, R. M., Iyer, V. R., and Lieb, J. D. (2007). FAIRE (Formaldehyde-Assisted Isolation of Regulatory Elements) isolates active regulatory elements from human chromatin. Genome Res. 17, 877-885.

Grosveld, F., Van Assendelft, G. B., Greaves, D. R., and Kollias, G. (1987). Position-independent, highlevel expression of the human betaglobin gene in transgenic mice. Cell 51, 975-985.

Haering, C. H., and Jessberger, R. (2012). Cohesin in determining chromosome architecture. Exp. Cell Res. 318, 1386-1393.

Hamada, H. (1986). Random isolation of gene activator elements from the human genome. Mol. Cell. Biol. 6, 4185-4194

Handoko, L., Xu, H., Li, G., Ngan, C. Y., Chew, E., Schnapp, M., et al. 
(2011). CTCF-mediated functional chromatin interactome in pluripotent cells. Nat. Genet. 43, 630-638.

Hanscombe, O., Whyatt, D., Fraser, P., Yannoutsos, N., Greaves, D., Dillon, N., et al. (1991). Importance of globin gene order for correct developmental expression. Genes Dev. 5, 1387-1394.

Harismendy, O., Notani, D., Song, X., Rahim, N. G., Tanasa, B., Heintzman, N., etal. (2011). 9p21 DNA variants associated with coronary artery disease impair interferon-gamma signalling response. Nature 470 , 264-268.

Hawkins, R. D., Hon, G. C., and Ren, B. (2010). Next-generation genomics: an integrative approach. Nat. Rev. Genet. 11, 476-486.

Hayday, A. C., Gillies, S. D., Saito, H., Wood, C., Wiman, K., Hayward, W. S., et al. (1984). Activation of a translocated human c-myc gene by an enhancer in the immunoglobulin heavy-chain locus. Nature 307 , 334-340.

He, A., Kong, S. W., Ma, Q., and Pu, W. T. (2011). Co-occupancy by multiple cardiac transcription factors identifies transcriptional enhancers active in heart. Proc. Natl. Acad. Sci. U.S.A. 108, 5632-5637.

Heintzman, N. D., Hon, G. C., Hawkins, R. D., Kheradpour, P., Stark, A., Harp, L. F., et al. (2009). Histone modifications at human enhancers reflect global cell-type-specific gene expression. Nature 459, 108-112.

Heintzman, N. D., Stuart, R. K., Hon, G., Fu, Y., Ching, C. W., Hawkins, R. D., et al. (2007). Distinct and predictive chromatin signatures of transcriptional promoters and enhancers in the human genome. Nat. Genet. 39 , 311-318.

Herold, M., Bartkuhn, M., and Renkawitz, R. (2012). CTCF: insights into insulator function during development. Development 139, 1045-1057.

Hesselberth, J. R., Chen, X., Zhang, Z., Sabo, P. J., Sandstrom, R., Reynolds, A. P., et al. (2009). Global mapping of protein-DNA interactions in vivo by digital genomic footprinting. Nat. Methods 6, 283-289.

Hoffman, M. M., Buske, O. J., Wang, J., Weng, Z., Bilmes, J. A., and Noble, W. S. (2012). Unsupervised pattern discovery in human chromatin structure through genomic segmentation. Nat. Methods 9, 473-476.

Hu, Q., Kwon, Y. S., Nunez, E., Cardamone, M. D., Hutt, K. R., Ohgi, K. A., et al. (2008). Enhancing nuclear receptor-induced transcription requires nuclear motor and
LSD1-dependent gene networking in interchromatin granules. Proc. Natl. Acad. Sci. U.S.A. 105, 19199-19204.

Jing, H., Vakoc, C. R., Ying, L., Mandat, S., Wang, H., Zheng, X., et al. (2008). Exchange of GATA factors mediates transitions in looped chromatin organization at a developmentally regulated gene locus. Mol. Cell 29, 232-242.

Johnson, D. S., Mortazavi, A., Myers, R. M., and Wold, B. (2007). Genomewide mapping of in vivo proteinDNA interactions. Science 316 1497-1502.

Kagey, M. H., Newman, J. J., Bilodeau, S., Zhan, Y., Orlando, D. A., Van Berkum, N. L., et al. (2010). Mediator and cohesin connect gene expression and chromatin architecture. Nature $467,430-435$.

Kasowski, M., Grubert, F., Heffelfinger, C., Hariharan, M., Asabere, A. Waszak, S. M., etal. (2010). Variation in transcription factor binding among humans. Science 328, 232-235.

Kellner, W. A., Ramos, E., Van Bortle, K., Takenaka, N., and Corces, V. G. (2012). Genome-wide phosphoacetylation of histone $\mathrm{H} 3$ at Drosophila enhancers and promoters. Genome Res. 22, 1081-1088.

Kim, S. I., Bultman, S. J., Kiefer, C. M., Dean, A., and Bresnick, E. H. (2009). BRG1 requirement for longrange interaction of a locus control region with a downstream promoter. Proc. Natl. Acad. Sci. U.S.A. 106 2259-2264.

Kim, T. K., Hemberg, M., Gray, J. M. Costa, A. M., Bear, D. M., Wu, J., et al. (2010). Widespread transcription at neuronal activity-regulated enhancers. Nature 465, 182-187.

Kioussis, D., Vanin, E., Delange, T., Flavell, R. A., and Grosveld, F. G. (1983). Beta-globin gene inactivation by DNA translocation in gamma beta-thalassaemia. Nature 306 662-666.

Kleinjan, D. A., and Lettice, L. A. (2008) Long-range gene control and genetic disease. Adv. Genet. 61, 339-388.

Koch, F., Fenouil, R., Gut, M., Cauchy, P., Albert, T. K., Zacarias-Cabeza, J., et al. (2011). Transcription initiation platforms and GTF recruitment at tissue-specific enhancers and promoters. Nat. Struct. Mol. Biol. 18, 956-963.

Kooren, J., Palstra, R. J., Klous, P., Splinter, E., Von Lindern, M., Grosveld, F., et al. (2007). Beta-globin active chromatin Hub formation in differentiating erythroid cells and in p45 NF-E2 knock-out mice. J. Biol. Chem. 282, 16544-16552.
Korostowski, L., Raval, A., Breuer, G., and Engel, N. (2011). Enhancerdriven chromatin interactions during development promote escape from silencing by a long non-coding RNA. Epigenetics Chromatin 4, 21.

Kowalczyk, M. S., Hughes, J. R., Garrick, D., Lynch, M. D., Sharpe, J. A., Sloane-Stanley, J. A., et al. (2012). Intragenic enhancers act as alternative promoters. Mol. Cell 45, 447-458.

Krebs, A. R., Karmodiya, K., LindahlAllen, M., Struhl, K., and Tora L. (2011). SAGA and ATAC histone acetyl transferase complexes regulate distinct sets of genes and ATAC defines a class of p300-independent enhancers. Mol. Cell 44, 410-423.

Kvon, E. Z., Stampfel, G., Yanez-Cuna, J. O., Dickson, B. J., and Stark, A (2012). HOT regions function as patterned developmental enhancers and have a distinct cis-regulatory signature. Genes Dev. 26, 908-913.

Lan, X., Witt, H., Katsumura, K., Ye, Z., Wang, Q., Bresnick, E. H., et al. (2012). Integration of $\mathrm{Hi}-\mathrm{C}$ and ChIP-seq data reveals distinct types of chromatin linkages. Nucleic Acids Res. 40, 7690-7704.

Laurell, T., Vandermeer, J. E., Wenger, A. M., Grigelioniene, G., Nordenskjold, A., Arner, M., et al. (2012). A novel 13 base pair insertion in the sonic hedgehog ZRS limb enhancer (ZRS/LMBR1) causes preaxial polydactyly with triphalangeal thumb. Hum. Mutat. 33, 1063-1066.

Leach, K. M., Nightingale, K., Igarashi, K., Levings, P. P., Engel, J. D., Becker, P. B., et al. (2001). Reconstitution of human beta-globin locus control region hypersensitive sites in the absence of chromatin assembly. Mol. Cell. Biol. 21, 2629-2640.

Li, G., Ruan, X., Auerbach, R. K., Sandhu, K. S., Zheng, M. Wang, P., etal. (2012). Extensive promoter-centered chromatin interactions provide a topological basis for transcription regulation. Cell 148, 84-98.

Lieberman-Aiden, E., Van Berkum, N. L., Williams, L., Imakaev, M., Ragoczy, T., Telling, A., et al. (2009). Comprehensive mapping of longrange interactions reveals folding principles of the human genome. Science 326, 289-293.

Liu, Z., Scannell, D. R., Eisen, M. B., and Tjian, R. (2011). Control of embryonic stem cell lineage commitment by core promoter factor, TAF3. Cell 146, 720-731.

Maksimenko, O., Golovnin, A., and Georgiev, P. (2008). Enhancerpromoter communication is regulated by insulator pairing in a Drosophila model bigenic locus. Mol. Cell. Biol. 28, 5469-5477.

Maston, G. A., Landt, S. G., Snyder, M., and Green, M. R. (2012). Characterization of enhancer function from genome-wide analyses. Annu. Rev. Genomics Hum. Genet. 13, 29-57.

Matthews, J. M., and Visvader, J. E. (2003). LIM-domain-binding protein 1: a multifunctional cofactor that interacts with diverse proteins. EMBO Rep. 4, 1132-1137.

May, D., Blow, M. J., Kaplan, T., Mcculley, D. J., Jensen, B. C., Akiyama, J. A., et al. (2011). Large-scale discovery of enhancers from human heart tissue. Nat. Genet. 44, 89-93.

McCord, R. P., Zhou, V. W., Yuh, T., and Bulyk, M. L. (2011). Distant cisregulatory elements in human skeletal muscle differentiation. Genomics 98, 401-411.

Meireles-Filho, A. C., and Stark, A. (2009). Comparative genomics of gene regulation-conservation and divergence of cis-regulatory information. Curr. Opin. Genet. Dev. 19, 565-570.

Melgar, M. F., Collins, F. S., and Sethupathy, P. (2011). Discovery of active enhancers through bidirectional expression of short transcripts. Genome Biol. 12, R113.

Mikkelsen, T. S., Ku, M., Jaffe, D. B., Issac, B., Lieberman, E., Giannoukos, G., et al. (2007). Genome-wide maps of chromatin state in pluripotent and lineage-committed cells. Nature 448 , 553-560.

Mikkelsen, T. S., Xu, Z., Zhang, X., Wang, L., Gimble, J. M., Lander, E. S., et al. (2010). Comparative epigenomic analysis of murine and human adipogenesis. Cell 143, 156-169.

Milot, E., Strouboulis, J., Trimborn, T., Wijgerde, M., De Boer, E., Langeveld, A., et al. (1996). Heterochromatin effects on the frequency and duration of LCR-mediated gene transcription. Cell 87, 105-114.

Mitchell, J. A., and Fraser, P. (2008). Transcription factories are nuclear subcompartments that remain in the absence of transcription. Genes Dev. $22,20-25$.

Miyamoto, K., Pasque, V., Jullien, J., and Gurdon, J. B. (2012). Nuclear actin polymerization is required for transcriptional reprogramming of Oct4 by oocytes. Genes Dev. 25, 946-958.

Musunuru, K., Strong, A., FrankKamenetsky, M., Lee, N. E., Ahfeldt, T., Sachs, K. V., et al. (2010). From noncoding variant to phenotype via SORT1 at the $1 \mathrm{p} 13$ cholesterol locus. Nature 466, 714-719. 
Nechaev, S., and Adelman, K. (2011). Pol II waiting in the starting gates: regulating the transition from transcription initiation into productive elongation. Biochim. Biophys. Acta 1809, 34-45.

Ong, C. T., and Corces, V. G. (2012). Enhancers: emerging roles in cell fate specification. EMBO Rep. 13, 423-430.

Orom, U. A., Derrien, T., Beringer, M., Gumireddy, K., Gardini, A., Bussotti, G., et al. (2010). Long noncoding RNAs with enhancer-like function in human cells. Cell 143, 46-58.

Orom, U. A., and Shiekhattar, R. (2011). Noncoding RNAs and enhancers: complications of a long-distance relationship. Trends Genet. 27, 433-439.

Palstra, R. J., Simonis, M., Klous, P., Brasset, E., Eijkelkamp, B., and De Laat, W. (2008). Maintenance of long-range DNA interactions after inhibition of ongoing RNA polymerase II transcription. PLoS ONE 3, e1661. doi: 10.1371/journal.pone. 0001661

Palstra, R. J., Tolhuis, B., Splinter, E., Nijmeijer, R., Grosveld, F., and De Laat, W. (2003). The beta-globin nuclear compartment in development and erythroid differentiation. Nat. Genet. 35, 190-194.

Papantonis, A., and Cook, P. R. (2010). Genome architecture and the role of transcription. Curr. Opin. Cell Biol. 22, 271-276.

Parelho, V., Hadjur, S., Spivakov, M., Leleu, M., Sauer, S., Gregson, H. C., et al. (2008). Cohesins functionally associate with CTCF on mammalian chromosome arms. Cell 132, 422-433.

Pekowska, A., Benoukraf, T., ZacariasCabeza, J., Belhocine, M., Koch, F., Holota, H., et al. (2011). H3K4 trimethylation provides an epigenetic signature of active enhancers. EMBO J. 30, 4198-4210.

Petrykowska, H. M., Vockley, C. M., and Elnitski, L. (2008). Detection and characterization of silencers and enhancer-blockers in the greater CFTR locus. Genome Res. 18, 1238-1246.

Pham, T. H., Benner, C., Lichtinger, M., Schwarzfischer, L., Hu, Y., Andreesen, R., et al. (2012). Dynamic epigenetic enhancer signatures reveal key transcription factors associated with monocytic differentiation states. Blood 119, e161-e171.

Pomerantz, M. M., Ahmadiyeh, N., Jia, L., Herman, P., Verzi, M. P., Doddapaneni, H., et al. (2009). The 8q24 cancer risk variant rs6983267 shows long-range interaction with MYC in colorectal cancer. Nat. Genet. 41, 882-884.

Raab, J. R., Chiu, J., Zhu, J., Katzman, S., Kurukuti, S., Wade, P. A., et al. (2011). Human tRNA genes function as chromatin insulators. EMBO J. 31, 330-350.

Raab, J. R., and Kamakaka, R. T. (2010). Insulators and promoters: closer than we think. Nat. Rev. Genet. 11, 439-446.

Rada-Iglesias, A., Bajpai, R., Swigut, T., Brugmann, S. A., Flynn, R. A., and Wysocka, J. (2011). A unique chromatin signature uncovers early developmental enhancers in humans. Nature 470, 279-283.

Rahimov, F., Marazita, M. L., Visel, A. Cooper, M. E., Hitchler, M. J., Rubini, M., et al. (2008). Disruption of an AP-2alpha binding site in an IRF6 enhancer is associated with cleft lip. Nat. Genet. 40, 1341-1347.

Ram, O., Goren, A., Amit, I., Shoresh, N., Yosef, N., Ernst, J., etal. (2011). Combinatorial patterning of chromatin regulators uncovered by genome-wide location analysis in human cells. Cell 147, 1628-1639.

Reddy, T. E., Gertz, J., Pauli, F., Kucera K. S., Varley, K. E., Newberry, K. M., et al. (2012). Effects of sequence variation on differential allelic transcription factor occupancy and gene expression. Genome Res. 22, 860-869.

Ren, X., Siegel, R., Kim, U. and Roeder, R. G. (2011). Direct interactions of OCA-B and TFIII regulate immunoglobulin heavychain gene transcription by facilitating enhancer-promoter communication. Mol. Cell 42, 342-355.

Robertson, G., Hirst, M., Bainbridge, M., Bilenky, M., Zhao, Y., Zeng, T., et al. (2007). Genome-wide profiles of STAT1 DNA association using chromatin immunoprecipitation and massively parallel sequencing. Nat Methods 4, 651-657.

Rodin, S., Kyrchanova, O., Pomerantseva, E., Parshikov, A., and Georgiev, P. (2007). New properties of Drosophila fab-7 insulator. Genetics 177, 113-121.

Royo, J. L., Hidalgo, C., Roncero, Y., Seda, M. A., Akalin, A., Lenhard, B., et al. (2011). Dissecting the transcriptional regulatory properties of human chromosome 16 highly conserved non-coding regions. PLoS ONE 6, e24824. doi: 10.1371/journal.pone. 0024824

Rubio, E. D., Reiss, D. J., Welcsh, P. L., Disteche, C. M., Filippova, G. N., Baliga, N. S., et al. (2008). CTCF physically links cohesin to chromatin. Proc. Natl. Acad. Sci. U.S.A. 105, 8309-8314.
Sabo, P. J., Kuehn, M. S., Thurman, R., Johnson, B. E., Johnson, E. M., Cao, H., et al. (2006). Genome-scale mapping of DNase I sensitivity in vivo using tiling DNA microarrays. Nat. Methods 3, 511-518.

Sawado, T., Halow, J., Bender, M. A. and Groudine, M. (2003). The beta -globin locus control region (LCR) functions primarily by enhancing the transition from transcription initiation to elongation. Genes Dev. 17, 1009-1018.

Schnetz, M. P., Bartels, C. F., Shastri, K., Balasubramanian, D., Zentner, G. E., Balaji, R., et al. (2009). Genomic distribution of CHD7 on chromatin tracks $\mathrm{H} 3 \mathrm{~K} 4$ methylation patterns. Genome Res. 19, 590-601.

Schnetz, M. P., Handoko, L., AkhtarZaidi, B., Bartels, C. F., Pereira, C. F., Fisher, A. G., et al. (2010). CHD7 targets active gene enhancer elements to modulate ES cell-specific gene expression. PLoS Genet. 6, e1001023. doi: 10.1371/journal.pgen.1001023

Sheng, Y., and Previti, C. (2011). Genomic features and computational identification of human microRNAs under long-range developmental regulation. BMC Genomics 12, 270. doi 10.1186/1471-2164-12-270

Simms, T. A., Dugas, S. L., Gremillion, J. C., Ibos, M. E., Dandurand, M. N., Toliver, T. T., et al. (2008). TFIIIC binding sites function as both heterochromatin barrier and chromatin insulators in Saccharomyces cerevisiae. Eukaryot. Cell 7 2078-2086.

Soler, E., Andrieu-Soler, C., De Boer, E., Bryne, J. C., Thongjuea, S., Stadhouders, R., etal. (2010). The genomewide dynamics of the binding of $\mathrm{Ldb}$ complexes during erythroid differentiation. Genes Dev. 24, 277-289.

Song, S. H., Hou, C., and Dean, A. (2007). A positive role for NLI/Ldb in long-range beta-globin locus control region function. Mol. Cell 28 , 810-822.

Soshnev, A. A., Li, X., Wehling, M. D., and Geyer, P. K. (2008). Context differences reveal insulator and activator functions of a $\mathrm{Su}(\mathrm{Hw})$ binding region. PLoS Genet. 4, e1000159. doi: 10.1371/journal.pgen.1000159

Spilianakis, C. G., and Flavell, R. A. (2004). Long-range intrachromosomal interactions in the Thelper type 2 cytokine locus. Nat. Immunol. 5 , 1017-1027.

Splinter, E., Heath, H., Kooren, J., Palstra, R. J., Klous, P., Grosveld, F., et al. (2006). CTCF mediates long-range chromatin looping and local histone modification in the beta-globin locus. Genes Dev. 20, 2349-2354.
Stadhouders, R., Thongjuea, S., Andrieu-Soler, C., Palstra, R. J., Bryne, J. C., Van Den Heuvel, A., et al. (2011). Dynamic long-range chromatin interactions control Myb proto-oncogene transcription during erythroid development. $E M B O ~ J .31$, 986-999.

Svotelis, A., Bianco, S., Madore, J., Huppe, G., Nordell-Markovits, A., Mes-Masson, A. M., et al. (2011). H3K27 demethylation by JMJD3 at a poised enhancer of anti-apoptotic gene BCL2 determines ERalpha ligand dependency. EMBO J. 30, 3947-3961.

Taberlay, P. C., Kelly, T. K., Liu, C. C., You, J. S., De Carvalho, D. D., Miranda, T. B., etal. (2011). Polycomb-repressed genes have permissive enhancers that initiate reprogramming. Cell 147, 1283-1294.

Tan, M., Luo, H., Lee, S., Jin, F., Yang, J. S., Montellier, E., et al. (2011). Identification of 67 histone marks and histone lysine crotonylation as a new type of histone modification. Cell 146, 1016-1028.

Taramelli, R., Kioussis, D., Vanin, E., Bartram, K., Groffen, J., Hurst, J., etal. (1986). Gamma delta betathalassaemias 1 and 2 are the result of a $100 \mathrm{kbp}$ deletion in the human beta-globin cluster. Nucleic Acids Res. 14, 7017-7029.

Tartof, K. D., and Henikoff, S. (1991). Trans-sensing effects from Drosophila to humans. Cell 65, 201-203.

Taslim, C., Chen, Z., Huang, K., Huang, T. H., Wang, Q., and Lin, S. (2012). Integrated analysis identifies a class of androgen-responsive genes regulated by short combinatorial long-range mechanism facilitated by CTCF. Nucleic Acids Res. 40, 4754-4764.

Teng, L., Firpi, H. A., and Tan, K. (2011). Enhancers in embryonic stem cells are enriched for transposable elements and genetic variations associated with cancers. Nucleic Acids Res. 39, 7371-7379.

Thanos, D., and Maniatis, T. (1995). Virus induction of human IFN beta gene expression requires the assembly of an enhanceosome. Cell 83, 1091-1100.

Tolhuis, B., Palstra, R. J., Splinter, E., Grosveld, F., and De Laat, W. (2002). Looping and interaction between hypersensitive sites in the active beta-globin locus. Mol. Cell 10, 1453-1465.

Tuan, D., Kong, S., and Hu, K. (1992). Transcription of the hypersensitive site HS2 enhancer in erythroid cells. Proc. Natl. Acad. Sci. U.S.A. 89, 11219-11223. 
Tuan, D., Solomon, W., Li, Q., and London, I. M. (1985). The "betalike-globin" gene domain in human erythroid cells. Proc. Natl. Acad. Sci. U.S.A. 82, 6384-6388.

Vakoc, C. R., Letting, D. L., Gheldof, N., Sawado, T., Bender, M. A., Groudine, M., et al. (2005). Proximity among distant regulatory elements at the beta-globin locus requires GATA-1 and FOG-1. Mol. Cell 17, 453-462.

Vernimmen, D., Lynch, M. D., De Gobbi, M., Garrick, D., Sharpe, J. A., Sloane-Stanley, J. A., et al. (2011). Polycomb eviction as a new distant enhancer function. Genes Dev. 25, 1583-1588.

Vieira, K. F., Levings, P. P., Hill, M. A., Crusselle, V. J., Kang, S. H., Engel, J. D., et al. (2004). Recruitment of transcription complexes to the betaglobin gene locus in vivo and in vitro. J. Biol. Chem. 279, 50350-50357.

Visel, A., Blow, M. J., Li, Z., Zhang, T., Akiyama, J. A., Holt, A., et al. (2009a). ChIP-seq accurately predicts tissuespecific activity of enhancers. Nature 457, 854-858.

Visel, A., Rubin, E. M., and Pennacchio, L. A. (2009b). Genomic views of distant-acting enhancers. Nature 461 , 199-205.

Visser, M., Kayser, M., and Palstra, R. J. (2012). HERC2 rs12913832 modulates human pigmentation by attenuating chromatin-loop formation between a long-range enhancer and the OCA2 promoter. Genome Res. 22, 446-455.

Wadman, I. A., Osada, H., Grutz, G. G., Agulnick, A. D., Westphal, H., Forster, A., et al. (1997). The
LIM-only protein Lmo2 is a bridging molecule assembling an erythroid, DNA-binding complex which includes the TAL1, E47, GATA-1 and Ldb1/NLI proteins. EMBO J. 16 , 3145-3157.

Wang, D., Garcia-Bassets, I., Benner, C., Li, W., Su, X., Zhou, Y., et al. (2011). Reprogramming transcription by distinct classes of enhancers functionally defined by eRNA. Nature 474, 390-394.

Wang, Z., Zang, C., Rosenfeld, J. A., Schones, D. E., Barski, A., Cuddapah, S., et al. (2008). Combinatorial patterns of histone acetylations and methylations in the human genome. Nat. Genet. 40, 897-903.

Wendt, K. S., and Peters, J. M. (2009) How cohesin and CTCF cooperate in regulating gene expression. Chromosome Res. 17, 201-214.

Wendt, K. S., Yoshida, K., Itoh, T., Bando, M., Koch, B., Schirghuber, E. et al. (2008). Cohesin mediates transcriptional insulation by CCCTCbinding factor. Nature 451, 796-801.

West, A. G., and Fraser, P. (2005) Remote control of gene transcription. Hum. Mol. Genet. 14(Suppl. 1), R101-R111.

Weth, O., and Renkawitz, R. (2011). CTCF function is modulated by neighboring DNA binding factors. Biochem. Cell Biol. 89, 459-468.

Whyte, W. A., Bilodeau, S., Orlando, D. A., Hoke, H. A., Frampton, G. M. Foster, C. T., et al. (2012). Enhancer decommissioning by LSD1 during embryonic stem cell differentiation. Nature 482, 221-225.

Wiench, M., John, S., Baek, S., Johnson, T. A., Sung, M. H., Escobar, T., et al. (2011). DNA methylation status predicts cell type-specific enhancer activity. EMBO J. 30, 3028-3039.

Wright, J. B., Brown, S. J., and Cole, M. D. (2010). Upregulation of cMYC in cis through a large chromatin loop linked to a cancer risk-associated single-nucleotide polymorphism in colorectal cancer cells. Mol. Cell. Biol. 30, 1411-1420.

Wright, S., Rosenthal, A., Flavell, R., and Grosveld, F. (1984). DNA sequences required for regulated expression of beta-globin genes in murine erythroleukemia cells. Cell 38 265-273.

Wu, C. (1980). The $5^{\prime}$ ends of Drosophila heat shock genes in chromatin are hypersensitive to DNase I. Nature 286, 854-860.

Yoo, E. J., Cooke, N. E., and Liebhaber, S. A. (2012). An RNA-independent linkage of noncoding transcription to long-range enhancer function. Mol. Cell. Biol. 32, 2020-2029.

Zentner, G. E., Tesar, P. J., and Scacheri, P. C. (2011). Epigenetic signatures distinguish multiple classes of enhancers with distinct cellular functions. Genome Res. 21, 1273-1283.

Zhang, X., Cowper-Sal Lari, R., Bailey, S. D., Moore, J. H., and Lupien, M. (2012). Integrative functional genomics identifies an enhancer looping to the SOX9 gene disrupted by the $17 \mathrm{q} 24.3$ prostate cancer risk locus. Genome Res. 22, 1437-1446.

Zhou, X., Baron, R. M., Hardin, M., Cho, M. H., Zielinski, J., Hawrylkiewicz, I., et al. (2012). Identification of a chronic obstructive pulmonary disease genetic determinant that regulates HHIP. Hum. Mol Genet. 21, 1325-1335.

Zhu, X., Ling, J., Zhang, L., Pi, W., Wu, M., and Tuan, D. (2007). A facilitated tracking and transcription mechanism of long-range enhancer function. Nucleic Acids Res. 35, 5532-5544.

Zhu, Y., Van Essen, D., and Saccani, S. (2012). Cell-type-specific control of enhancer activity by H3K9 trimethylation. Mol. Cell 46, 408-423.

Conflict of Interest Statement: The authors declare that the research was conducted in the absence of any commercial or financial relationships that could be construed as a potential conflict of interest.

Received: 09 July 2012; paper pending published: 23 July 2012; accepted: 12 September 2012; published online: 28 September 2012.

Citation: Palstra R-I and Grosveld F (2012) Transcription factor binding at enhancers: shaping a genomic regulatory landscape in flux. Front. Gene. 3:195. doi: 10.3389/fgene.2012.00195

This article was submitted to Frontiers in Epigenomics, a specialty of Frontiers in Genetics.

Copyright (๑) 2012 Palstra and Grosveld. This is an open-access article distributed under the terms of the Creative Commons Attribution License, which permits use, distribution and reproduction in other forums, provided the original authors and source are credited and subject to any copyright notices concerning any third-party graphics etc. 